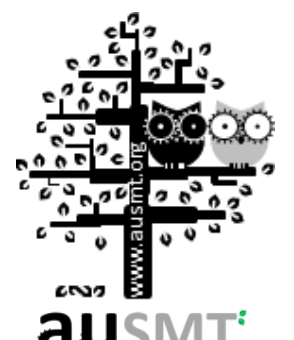

\title{
Trend Analysis for the Market and Application Development of 3D Printing
}

\section{Chin-Ching Yeh*}

Industrial Economics and Knowledge Center (IEK), Industrial Technology Research Institute (ITRI), Taiwan

(Received 1 January 2014; Published on line 1 March 2014)

*Corresponding author: yyhuang@itri.org.tw

DOI: $10.5875 / a u s m t . v 4 i 1.597$

\begin{abstract}
In 2011, the Economist newspaper declared the advent of 3D printing, also known as Additive Manufacturing (AM), to herald the start of the Third Industrial Revolution. Chris Anderson, originator of the "long-tail theory", not only authored Makers, a book on3D printing, but also co-founded 3D Robotics to realize his vision for the potential of 3D printing by applying his perspectives embedded in his book. Nevertheless, opposing viewpoints suggest that 3D printing may not be the game changer its proponents claim. The article explores the technical classification and market growth potential of 3D printing, and analyzes the main markets and countries as well as the application scope of 3D printing.
\end{abstract}

Keywords: 3D printing; Additive Manufacturing; Rapid Prototyping

\section{The Seven Process Techniques of 3D Printing}

In 2009, the American Society for Testing and Materials (ASTM) officially introduced the term Additive Manufacturing to replace Rapid Prototyping (RP), Rapid Manufacturing (RM), and 3D Printing (3DP), and established a technical committee to stipulate relevant standards. The ASTM collaborated with scholars and classified the AM processinto seven categories, as shown in Table 1, including Vat Photopolymerization, Material Jetting, Binder Jetting, Material Extrusion, Powder Bed Fusion, Sheet Lamination, and Directed Energy Deposition. Each technique coincides with different materials and application markets, but they share the same development objectives which center on supplying diverse materials, increasing production efficiency, improving geometric accuracy and surface roughness, enhancing material and mechanical properties and reducing equipment and material costs.

\section{Rapid Growth of the 3D Printing Market}

According to Wohlers Report 2013, the global market for AM products and services reached USD \$2.2 billion in 2012, an increase of $28.6 \%$ from the year before. The compound annual growth rate (CAGR) of the AM industry in recent years has been steady in a range between $25 \%$ and $30 \%$, and double-digit growth is to be expected in the coming years. It is anticipated that the market for AM products and services will reach USD \$3.7 billion by 2015 and USD $\$ 6.5$ billion by 2019 (see Figure $1)$. 
Table 1.The Seven Techniques of Additive Manufacturing.

\begin{tabular}{|c|c|c|}
\hline Production Process & Material & Market \\
\hline Vat Photo polymerization & Photopolymers & Prototyping \\
\hline Material Jetting & Polymers, Waxes & Prototyping, Casting Pattern \\
\hline Binder Jetting & Polymers, Metals, Foundry Sand & Prototyping, Casting Molds, Direct Part \\
\hline Material Extrusion & Polymers & Prototyping \\
\hline Powder Bed Fusion & Polymers, Metals & Prototyping, Direct Part \\
\hline Sheet Lamination & Paper, Metals & Prototyping, Direct Part \\
\hline Directed Energy Deposition & Metals & Repair, Direct Part \\
\hline
\end{tabular}

Source: ASTM; compiled by the Industrial Economics \& Knowledge Center (IEK), Industrial Technology Research Institute of Taiwan (ITRI; 2013/07).

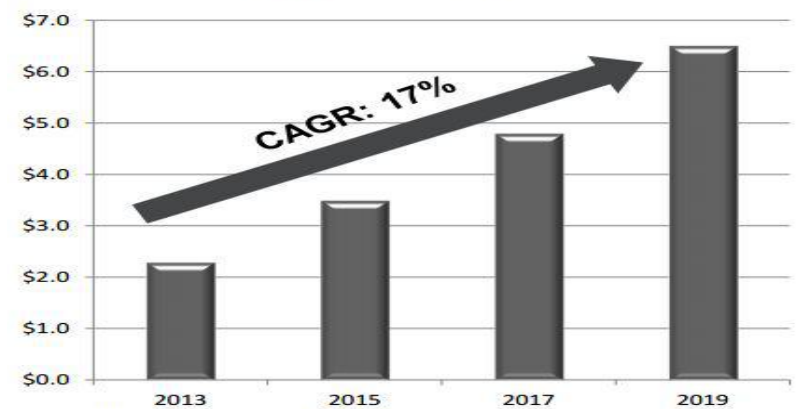

Figure 1. Scale projection for 3D printing.

Source: Wohlers Report (2013/01); compiled by ITRI IEK (2013/04).

\section{The United States is Currently the Largest Consumer Market for 3D Printing Equipment}

Wohlers Report 2012 indicated that the U.S. accounted for $38 \%$ of overall global installations of AM production systems, followed by Japan (9.7\%), Germany (9.4\%) and China (8.7\%). AM systems range from small, personalized systems to large-scale professional installations. Of the 30 companies that manufacture and sell professional AM equipment, 16 are located in Europe, 7 in China, 5 in the U.S. and 2 in Japan (Figure 2).

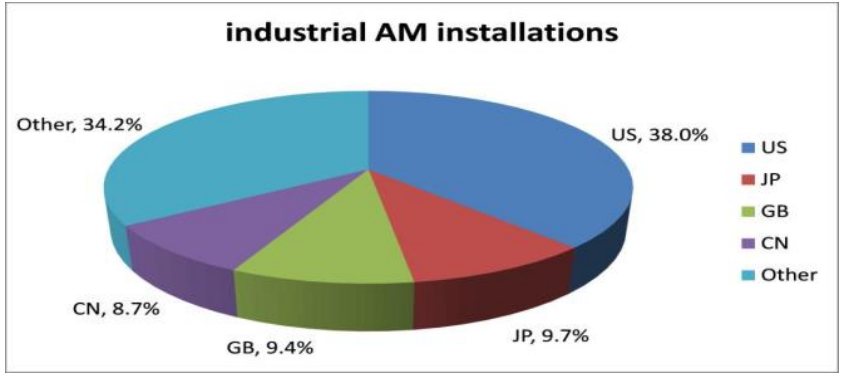

Figure 2. 2012 statistics for AM installations.

Source: Wohlers Report (2013/01); compiled byITRI IEK (2013/04).

\section{Consumer Products/Electronics are the Most Popular Application}

3D printing aims to achieve "personalized designs and minimum wastage", featuring high customization, rapidness, and flexibility with high energy savings and cost-performance ratio. Recent years have seen the development of diverse applied materials and improved product durability and precision, allowing AM products to evolve from display prototypes into directly applicable functional parts. Consequently, the application scope and market size of AM products and services has been rapidly and widely adopted for industrial mold production in a range of markets including motor vehicles, aerospace devices, medical/dental appliances, jewelry and consumer products, and is also widely used in the creative arts.

According to the Wohlers Report 2012, the largest application demand for 3D printing in 2012 was the consumer products/electronics market, occupying $22 \%$ of the overall application market. The second largest demand lay in the motor vehicles market (18.6\%), in which related techniques were primarily used for the modeling of vehicles and parts, providing time and cost savings from $R \& D$ to production. In the future, the motor vehicles market will seek to apply 3D printing techniques directly into the manufacturing of products and molds. The third largest application market was the medical/dental market, occupying $16.4 \%$ of the overall application market. 3D printing techniques were first applied in the dental market because of the uniqueness of individual teeth and dentures. Future developments may include the direct printing of prosthetics or functioning human organs.

Chin-Ching Yeh is a Researcher in the Machinery \& System Research Division at Industrial Economics and Knowledge Center. He got his master degree in Industrial Education from National Changhua University of Education, Taiwan. His research topics focus on Tablet PC, TFT LCD, OLED, Flexible Display, Machinery, Robotics, and so on 


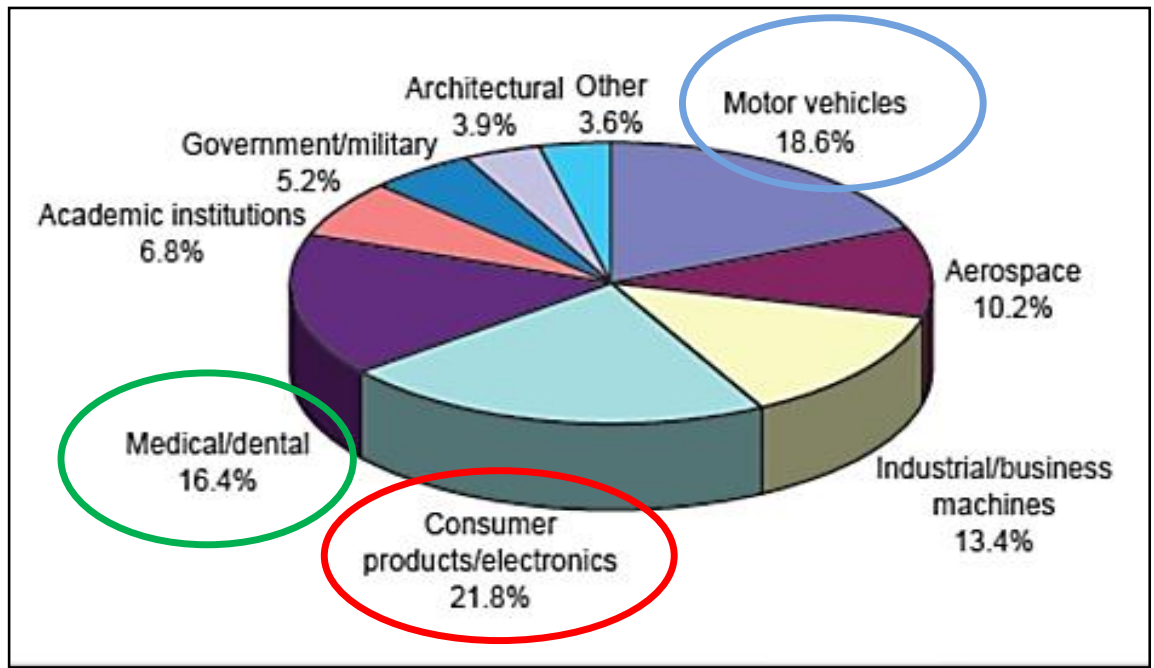

Figure 3. Analyzing the application market for 3D printing.

Source: Wohlers Report (2013/01); complied by ITRI IEK (2013/04).

\section{Conclusion}

3D printing is not a new technology. Since the 1980s, 3D Systems has made significant investments in the $R \& D$ and production of related techniques and products. Due to the characteristics of 3D printing, early techniques could only be applied to productmodels, thus reducing $R \& D$ time, or to the manufacture of a limited variety of products in small quantities (under 1,000 units). In addition, the installation of 3D printing equipment was extremely costly. However, following the expiration of related patents and increased Internet penetration, 3D printing is once again attracting considerable attention and investment, which could potentially accelerate the promotion of related techniques. Moreover, advancements in the development of materials and process techniques have exponentially enhanced the application scope, precision, and reliability of 3D printing techniques, and 3D printing techniques are likely to be more extensively and comprehensively applied in the near future. 